\title{
Response to cryptorchidism of the testis and epididymis of the opossum (Didelphis virginiana)
}

\author{
Jane N. Scott, H. Ira Fritz and F. Nagy \\ Departments of Anatomy and Biological Chemistry, Wright State University School of \\ Medicine, Dayton, Ohio 45435, U.S.A.
}

\begin{abstract}
Summary. Adult male opossums, Didelphis virginiana, were rendered hemicryptorchid for 35 days. The cryptorchid testis exhibited a significant reduction in weight, while the contralateral testis had a compensatory weight gain compared with testes of untreated animals. Histological changes in the cryptorchid testis included fibrosis of the tunica propria, involution of the seminiferous tubules and an apparent increase in the interstitial tissue. Many seminiferous tubules were empty and germinal cells were absent. Some Sertoli cells persisted, but the cytoplasm was vacuolated. Cryptorchid testes were characterized by mononuclear leucocytic invasion around the tubules, and some eosinophils were observed. Cryptorchidism in the opossum may induce a reaction similar to experimental orchitis.
\end{abstract}

\section{Introduction}

There is little information regarding the male reproductive system of the opossum, Didelphis virginiana. The testes and epididymides are exteriorized in a prepenile scrotum suggesting that spermatogenesis in the testis and sperm maturation in the epididymis require an optimum temperature lower than deep body temperature. Compared with eutherian mammals, the opossum has a low body temperature and cannot efficiently regulate body temperature in response to wide-ranging environmental temperatures (Reynolds, 1952). Biggers (1966) suggested that the regulation of scrotal temperature may be augmented by the heavily pigmented layer of the tunica vaginalis which may act as a black body radiator.

The present experiment was undertaken to provide information regarding the effects of prolonged exposure to elevated temperature on the opossum testis and epididymis.

\section{Materials and Methods}

Five adult male opossums were anaesthetized with an intraperitoneal injection of Equi-thesin (active agents $9.7 \mathrm{mg}$ pentobarbital $/ \mathrm{ml}$ and $42.5 \mathrm{mg}$ chloral hydrate/ml: Jensen-Salsbery Laboratories, Kansas City, U.S.A.) in a dose of $2.2 \mathrm{ml} / \mathrm{kg}$ body weight. The scrotal sac, the lower abdominal area and the inguinal areas were shaved and washed with an antiseptic solution. Sterile technique was used throughout the operation. Unilateral cryptorchidism was produced by a two-step surgical procedure. First, a scrotal incision was made and the testis, tunica vaginalis and spermatic cord were freed by blunt dissection. A second incision approximately 4-6 cm long was made lateral to the isopubic bar of the pubic bone into the abdominal cavity. Beneath the skin a tunnel was made to connect the two incisions and to allow passage of the testis into the abdominal cavity. To avoid injury to the spermatic cord, the abdominal incision was distal to the natural entry of the cord into the abdominal cavity. This meant that the cord was looped above 
the abdominal musculature before returning into the abdominal cavity. The abdominal incision was sutured and the skin closed with surgical clips. The scrotal incision was left open to facilitate drainage of the tunnel and the scrotum. One side of the scrotal sac was left intact as a control. The side of the scrotum chosen for control or experimental treatment was selected randomly. Testes and epididymides were obtained from 5 untreated animals to control for possible effects of hemicryptorchidism on the contralateral testis.

The animals were gonadectomized 35 days after surgery. Testes and epididymides were excised, weighed, and fixed in Carnoy's or Helly's fluid. The tissues were processed for paraffinwax embedding, sectioned at $7 \mu \mathrm{m}$ and stained with haematoxylin and eosin, Mallory's aniline blue or periodic acid-Schiff reagent.

Student's $t$ test was used to analyse the data, using $P \leqslant 0.05$ as the level of significance.

\section{Results}

\section{Weights of the testes and epididymides}

As shown in Table 1 the testes which were placed in the abdomen weighed $54 \%$ less than the contralateral scrotal testes, and testes from the untreated animals weighed $23 \%$ less than the scrotal testes of the hemicryptorchid animals. Abdominal epididymides were lighter than those associated with the contralateral scrotal testis.

Table 1. The effects of experimental unilateral cryptorchidism on the weights (mean \pm s.e.m.) of the testis and epididymis of opossums

\begin{tabular}{|c|c|c|c|}
\hline & $\begin{array}{c}\text { No. of } \\
\text { animals }\end{array}$ & $\begin{array}{l}\text { Testis wt } \\
(\mathrm{g})\end{array}$ & $\begin{array}{l}\text { Epididymis wt } \\
\text { (g) }\end{array}$ \\
\hline Experimental animals & 5 & & \\
\hline Scrotal side & & $1.60 \pm 0.12$ & $0.63 \pm 0.03$ \\
\hline Cryptorchid side & & $0.73 \pm 0.14^{*} \dagger$ & $0.55 \pm 0.02^{*}$ \\
\hline Control animals (untreated) & 5 & $1.23 \pm 0.05^{*}$ & $0.58 \pm 0.02$ \\
\hline
\end{tabular}

* Significantly different from the scrotal tissues, $P \leqslant 0.05$.

$\dagger$ Significantly different from the control tissues, $P \leqslant 0.05$.

\section{Histological changes}

Before the testes were placed in the abdominal cavity, the tunica vaginalis was heavily pigmented (P1. 1, Fig. 1). However, after 35 days in the abdominal cavity the pigmentation was greatly reduced (Pl. 1, Fig. 2) and there were increased amounts of fibrous tissue. Pigmentation from the tunicae was sometimes observed extending into the tissue surrounding the spermatic cord. In one animal the tunica had adhered to the abdominal wall and pigmentation was present in the associated musculature.

The scrotal testes of the experimental and control animals were generally histologically similar although there was some cytoplasmic vacuolation in the Leydig cells of the experimental animals.

Striking changes were evident in the cryptorchid testes. The tunicae albugineae were greatly thickened, apparently due to an increase in collagenous fibres, and there was a decrease in the linear organization of the fibres and cells. Occasionally foci of leucocytic invasion were seen in the innermost layer of the tunic in the cryptorchid testes.

Compared to the contralateral scrotal testes (Pl. 1, Fig. 3), the cryptorchid gonads (Pl. 1, Fig. 4; Pl. 2, Fig. 5) showed a significant reduction in the diameter of the seminiferous tubules. 

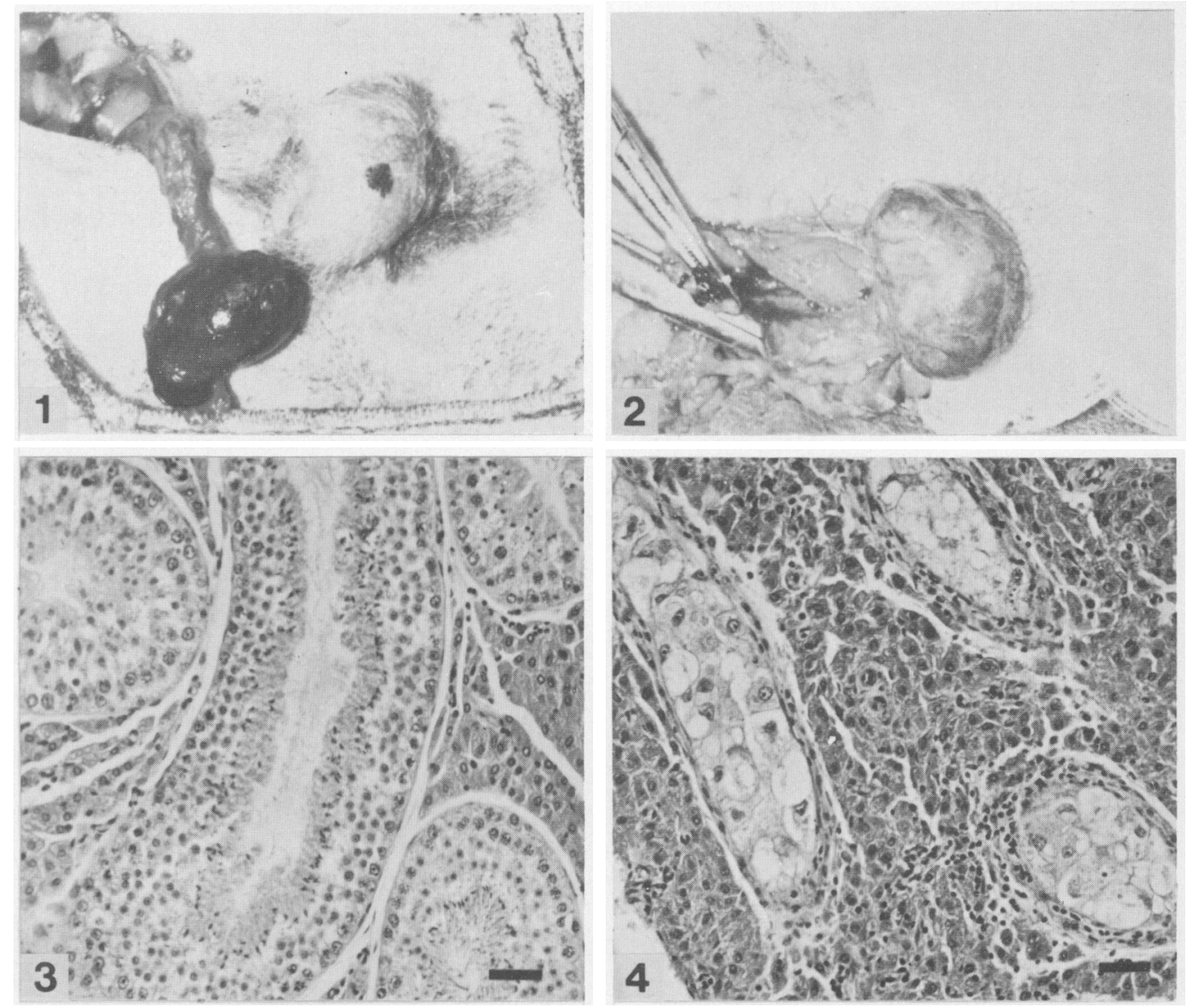

Fig. 1. Normal appearance of the pigmented tunica vaginalis.

Fig. 2. Appearance of the same tunica vaginalis after 35 days in the abdominal cavity. Note the diminished coloration.

Fig. 3. Section of a scrotal testis showing normal spermatogenesis and numerous Leydig cells. $\mathrm{H} \& \mathrm{E}$, bar $=50 \mu \mathrm{m}$.

Fig. 4. Section of a cryptorchid testis showing the apparent increase of Leydig cells. Only Sertoli cells with vacuolated cytoplasm are present in the seminiferous tubules. Leucocytic invasion is associated with the tubule at the left. $\mathrm{H} \& \mathrm{E}, \mathrm{bar}=50 \mu \mathrm{m}$. 


\section{PLATE 2}
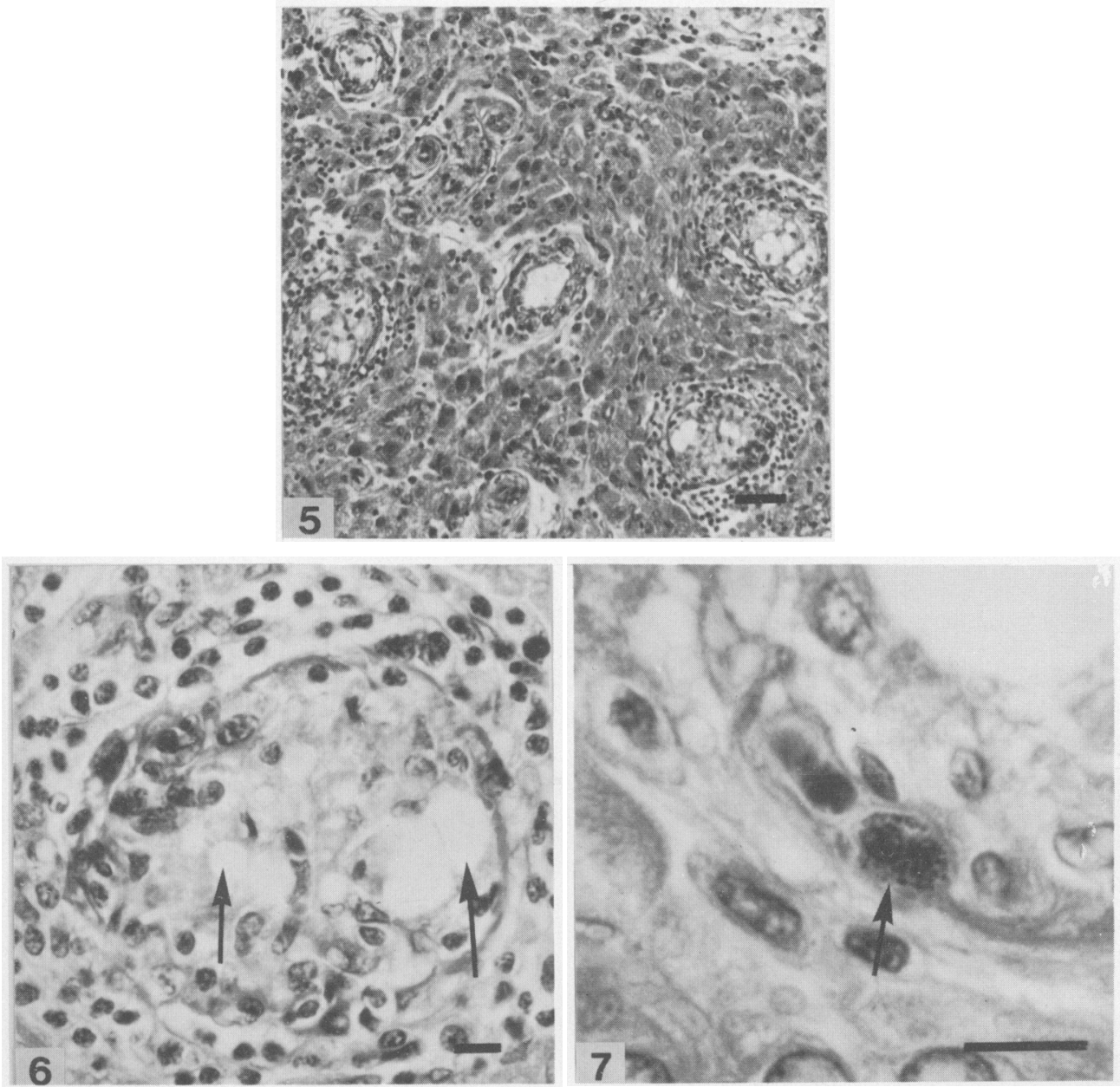

Fig. 5. Section of a cryptorchid testis demonstrating empty seminiferous tubules. Tubules at lower right and left are surrounded by leucocytes. Sertoli cells are absent from all tubules. H \& $\mathrm{E}, \mathrm{bar}=50 \mu \mathrm{m}$.

Fig. 6. Section of a cryptorchid testis showing a seminiferous tubule surrounded by mononuclear leucocytes and filled with similar cells. Note the large vacuoles (arrows) suggestive of lipid deposition. $\mathrm{H} \& \mathrm{E}$, bar $=10 \mu \mathrm{m}$.

Fig. 7. Section of a cryptorchid testis showing an eosinophil (arrow) within the tunica propria of a seminiferous tubule. The lumen (upper right) is empty. $\mathrm{H} \& \mathrm{E}, \mathrm{bar}=10 \mu \mathrm{m}$. 
There was an apparent increase in the amount of interstitial tissue, especially in the number of Leydig cells. The cytoplasm of the Leydig cells in the cryptorchid testes stained more intensely and the nuclei were more basophilic than those of the contralateral scrotal testes.

The seminiferous tubule changes in the cryptorchid testes consistently included an apparent absence of germinal cells and thickened tunicae propriae. The tunica propria of seminiferous tubules in control testes was quite thin and appeared to consist of one layer of cells and a small amount of fibrous tissue, possibly collagen. In the cryptorchid testes the tunica propria consisted of 3 or 4 layers of cells, and there was an apparent increase in collagen (Pl. 2, Fig. 5). In several cryptorchid testes the only cells present in the seminiferous tubules were Sertoli cells with irregular and displaced nuclei (Pl. 1, Fig. 4) and often cytoplasmic vacuolation. Occasionally the lumina of the tubules were empty and a PAS-positive deposit lined the luminal surface. In other tubules the Sertoli cells appeared to be replaced by mononuclear leucocytes. Numerous large vacuoles suggestive of lipid deposition were observed in the lumina (Pl. 2, Fig. 5). Mononuclear leucocytic invasion frequently occurred around seminiferous tubules and appeared to disrupt the limiting membrane ( $\mathrm{Pl}$. 2, Fig. 6). Eosinophils were seen in the tissue surrounding the seminiferous tubules and also within or traversing the tunica propria (Pl. 2, Fig. 7).

Epididymides which were retained in the abdomen were devoid of spermatozoa and had a narrower lumen than control epididymides, but no other morphological changes were noted.

\section{Discussion}

There has been some interest in the functional relationship between testicular temperature regulation in New World marsupials and the melanized tunica vaginalis (Biggers, 1966). Scott \& Fritz (1979) observed normal spermatogenesis in the testes and sperm-pairing in the epididymides of opossums in which the testes were surrounded by a non-pigmented tunica. The present study presents the first report of the effects of increased temperature on the testis and epididymis of a marsupial.

In the present experiment, the surgical technique used to make the opossum hemicryptorchid left the pigmented tunica vaginalis around the testis and epididymidis. Increased fibrous tissue in the tunica may have contributed to the apparent loss of pigmentation but movement of pigment out of the tunica also seemed to have occurred because pigment was observed in nearby tissues. The elevated temperature may have stimulated migration of the melanocytes, or macrophages containing phagocytosed pigment after cell death may have migrated to the surrounding tissues.

Unilateral cryptorchidism results in a compensatory increase in the size of the scrotal testis of men (Laron \& Zilka, 1969), rams (Blackshaw \& Samisoni, 1967) and rats (Clegg, 1961). This was also demonstrated for the opossums in the present study, even after only 35 days. In hemicryptorchid rats, Clegg (1965) attributed the compensatory increase to hypertrophy and hyperplasia of the Leydig cells. However, van Straaten \& Wensing (1977) found hypertrophy of all testicular elements in the scrotal testis of hemicryptorchid pigs. In our study, the absence of changes in the germinal epithelium and apparent increased size due to vacuolation in Leydig cells suggest that hypertrophy of these cells caused the weight increase of the scrotal testes.

The absence of a significant difference between the mean weight of the scrotal epididymides and that of the control epididymides suggests that androgen production was maintained at a normal level in the hemicryptorchid animals. The lower weight of the abdominal epididymides was partly due to the complete absence of spermatozoa.

The involution of seminiferous tubules, fibrosis of the surrounding tunica propria and apparent increase of interstitial tissue seen in the opossum cryptorchid testis are commonly noted in cryptorchid testes of other species, including rat and man (Nelson, 1951; Leeson, 1966; Leeson \& Leeson, 1970). However, these effects probably do not represent a maximal response 
in the opossum because of the subcutaneous loop of the spermatic artery and vein which could have resulted in some cooling of the blood supply to the testis.

The absence of germinal cells and loss of Sertoli cells in many seminiferous tubules after 35 days exposure to elevated temperature suggests that the opossum testis is more temperaturesensitive than testes of other species. Germinal cells and Sertoli cells have been observed in cryptorchid testes of adult men (Sohval, 1954; Leeson, 1966) and germinal cells have been seen in rat testes after 100 days of cryptorchidism (Nelson, 1951).

Seminiferous tubules showing complete aspermatogenesis in the present study were frequently surrounded by mononuclear leucocytes and often contained some of these cells. Eosinophils characterized the leucocytic invasion and were noted crossing the tunica propria. These observations are similar to those made after induction of experimental autoimnune allergic orchitis in the guinea-pigs by immunization with testicular extracts (Waksman, 1959; Johnson, 1970a). Induction of experimental autoimmune orchitis is thought to result from breakdown of the blood-testis barrier (Johnson, 1970b). The Sertoli cells are responsible for the blood-testis barrier which normally isolates the contents of the seminiferous tubules (Setchell, 1977); however, effects of temperature on the blood-testis barrier have not been conclusively demonstrated. Main \& Waites (1977) noted that in rats the barrier was not altered by exposure to increased temperatures for $1 \mathrm{~h}$. In the present study of the opossum, the longer exposure to elevated temperature caused degeneration and loss of Sertoli cells which may have disrupted the blood-testis barrier, thus allowing contents of the tubules to leak into surrounding tissue. Proteins released from degenerating germinal cells could have induced a reaction similar to that of experimental orchitis.

We thank Robert Scott for help with the photography and Donald and Janet Gum for help in obtaining animals. Financial support was provided in part by a Biomedical Research Grant from Wright State University School of Medicine.

\section{References}

Biggers, J.D. (1966) Reproduction in male marsupials. Symp. zool. Soc. Lond. 15, 251-280.

Blackshaw, A.W. \& Samisoni, J.I. (1967) The testes of the cryptorchid ram. Res. vet. Sci. 8, 187-194.

Clegg, E.J. (1961) Further studies on artificial cryptorchidism: quantitative changes in the interstitial cells of the rat testis. J. Endocr. 21, 433-441.

Clegg, E.J. (1965) Studies on artificial cryptorchidism: the histological appearances of unilateral and bilateral abdominal testes in the rat. J. Endocr. 33, 270-279.

Johnson, M.H. (1970a) Changes in the blood-testis barrier of the guinea-pig in relation to histological damage following iso-immunization with testis. $J$. Reprod. Fert. 22, 119-127.

Johnson, M.H. (1970b) An immunologic barrier in the guinea-pig testis. J. Path. 101, 129-138.

Laron, Z. \& Zilka, E. (1969) Compensatory hypertrophy of testicle in unilateral cryptorchidism. J. clin. Endocr. Metab. 29, 1409-1419.

Leeson, C.R. (1966) An electron microscopic study of cryptorchid and scrotal human testes, with special reference to pubertal maturation. Invest. Urol. 3, 498-511.

Leeson, T. S. \& Leeson, C.R. (1970) Experimental cryptorchidism in the rat. A light and electron microscope study. Invest. Urol. 8, 127-144.
Main, S.J. \& Waites, G.M.H. (1977) The blood-testis barrier and temperature damage to the testis of the rat. J. Reprod. Fert. 51, 439-450.

Nelson, W.O. (1951) Mammalian spermatogenesis: effect of experimental cryptorchidism in the rat and non-descent of the testis in man. Recent Prog. Horm. Res. 6, 29-62.

Reynolds, H.C. (1952) Studies on reproduction in the opossum (Didelphis virginiana). Univ. Calif. Publs Zool. 52, 223-284.

Scott, J.N. \& Fritz, H.I. (1979) Nonpigmented tunica vaginalis testis in the opossum. Ohio J. Sci. 79, 79-80.

Setchell, B.P. (1977) The blood-testis barrier. In Frontiers in Reproduction and Fertility Control, vol. 2, pp. 338-352. Eds R. O. Greep \& M. A. Koblinsky. MIT Press, Cambridge, Massachusetts.

Sohval, A.R. (1954) Histopathology of cryptorchidism. Am. J. Med. 16, 346-362.

van Straaten, H.W.M. \& Wensing, C.J.G. (1977) Histomorphometric aspects of testicular morphogenesis in the naturally unilateral cryptorchid pig. Biol. Reprod. 17, 473-479.

Waksman, B.H. (1959) A histologic study of the autoallergic testis lesion in the guinea pig. J. exp. Med. 109, 311-313. 